\title{
Educational and vocational goal disruption in adolescent and young adult cancer survivors
}

Janine Vetsch ${ }^{1,2,3}$, Claire E. Wakefield ${ }^{2,3}$, Brittany C. McGill ${ }^{2,3}$, Richard J. Cohn ${ }^{2,3}$, Sarah J. Ellis $^{2,3}$, Natalie Stefanic ${ }^{4}$, Susan M. Sawyer ${ }^{5}$, Brad Zebrack ${ }^{6}$, Ursula M. Sansom-Daly ${ }^{2,3}$

1. University of Lucerne, Department of Health Sciences and Health Policy, Lucerne, Switzerland.

2. School of Women's \& Children's Health, UNSW Sydney, Australia.

3. Kids Cancer Centre, Sydney Children's Hospital, Randwick, NSW 2031, Australia.

4. Centre for Medical Psychology and Evidence-based Decision-making (CeMPED), School of Psychology, the University of Sydney, Camperdown, NSW 2006, Australia

5. Department of Paediatrics, the University of Melbourne, Parkville, Victoria, 3052; Centre for Adolescent Health, Royal Children's Hospital, Flemington Road, Parkville, Victoria 3052; and Murdoch Children's Research Institute, Parkville Victoria 3052, Australia.

6. University of Michigan, School of Social Work, Ann Arbor, Michigan, USA.

Corresponding author: Ursula Sansom-Daly, Behavioural Sciences Unit, Kids Cancer Centre, Level 1 South Wing, Sydney Children's Hospital, High St, Randwick, NSW, AUSTRALIA, 2031. Ph: +612 9382-3114 Fax: +61293821789 Email: ursula@unsw.edu.au

This is the author manuscript accepted for publication and has undergone full peer review but has not been through the copyediting, typesetting, pagination and proofreading process, which may lead to differences between this version and the Version of Record. Please cite this article as doi: $10.1002 /$ pon. 4525

This article is protected by copyright. All rights reserved. 


\begin{abstract}
Objective: Cancer in adolescents and young adults (AYAs) can interrupt important developmental milestones. Absence from school and time lost from work, together with the physical impacts of treatment on energy and cognition, can disrupt educational and vocational goals. The purpose of this paper is to report on AYA cancer survivors' experiences of reintegration into school and/or work and to describe perceived changes in their educational and vocational goals.
\end{abstract}

Methods: AYAs recruited from seven hospitals in Australia, aged 15-26years and $\leq 24$ months post-treatment, were interviewed using the Psychosocial Adjustment to Illness Scale (PAIS). Responses were analysed to determine the extent of, and explanations for, cancer's effect on school/work.

Results: Forty-two AYA cancer survivors (50\%female) participated. Compared with their previous vocational functioning, 12(28.6\%) were scored as experiencing mild impairment, 14(33.3\%) moderate impairment, and 3(7.1\%) marked impairment. AYAs described difficulties reintegrating to school/work as a result of cognitive impacts such as concentration problems and physical impacts of their treatment, including fatigue. Despite these reported difficulties, the majority indicated that their vocation goals were of equal or greater importance than before diagnosis $(26 / 42 ; 62 \%)$, and most AYAs did not see their performance as compromised (23/42;55\%). Many survivors described a positive shift in life goals and priorities. The theme of goal conflict emerged where AYAs reported compromised abilities to achieve their goals. 
Conclusions: The physical and cognitive impacts of treatment can make returning to school/work challenging for AYA cancer survivors. AYAs experiencing difficulties may benefit from additional supports to facilitate meaningful engagement with their chosen educational/vocational goals.

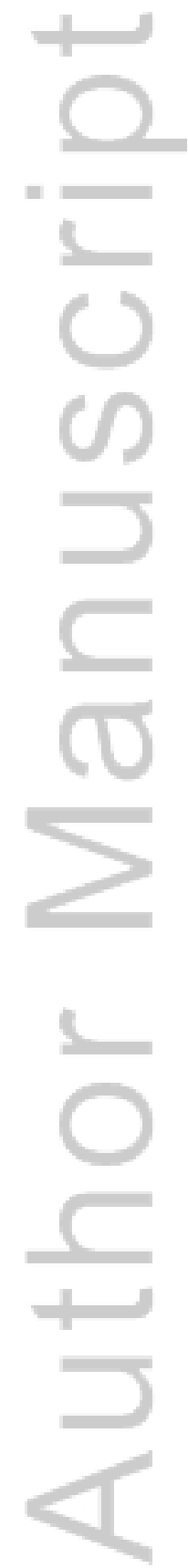

This article is protected by copyright. All rights reserved. 


\section{Introduction}

Education is key to adolescent health and well-being and is a driving force of socioeconomic progress (1). Cancer in adolescents and young adults (AYAs) interrupts this crucial developmental phase characterised, in part, by transition from the secondary to tertiary education system, and by movement into the workforce (2-5). A cancer diagnosis puts AYAs at high risk for disruptions or delays in achieving personal, educational and vocational goals (4-6). Cancer may also hinder AYAs' financial independence (5), with lost productivity including employment disability, fewer hours worked and more work days lost (7). In Australia it is estimated that cancer among AYAs accounts for 8785 disability adjusted life years lost (8).

Engagement with personally meaningful work is important for overall health and financial security in all AYAs (9). For those with cancer, the ability to return to 'a new normal' after diagnosis; that is, reintegration into personal and/or professional life while also acknowledging the impact of the cancer experience, is crucial $(10,11)$. Returning to school or work to maintain educational and vocational pursuits improves quality of life, reduces social isolation and fosters the self-esteem of AYA and adult cancer patients and survivors $(5,9)$. Recent US-based research found that engagement in school or work was associated with a reduction in distress over time in AYA cancer patients (12). However, AYAs with cancer can experience barriers during this transition. Symptoms such as fatigue, anxiety, and poor communication between families and the broader school community might hinder successful school re-engagement in AYAs $(13,14)$. Families often require support to navigate the education system and advocate effectively for their AYA child's academic needs beyond the 
immediate re-entry period (13). Factors related to difficulties returning to work include high treatment intensity, lack of insurance, and resigning from work after diagnosis (6). In a review in adult cancer settings it was shown that both heavy work (eg physical labour, such as lifting) and chemotherapy were negatively associated with return to work (15).

Life goals, including both vocational and personal goals are critical in the AYA years, and are often adapted or shifted by a cancer diagnosis (9). Life goals, are defined as internal representations of a desired state (16). Schwartz and colleagues' theoretical framework on the nature and impact of personal goals in children and adolescents with a chronic health condition posits that setting, prioritising and working towards a goal is associated with positive outcomes such as better quality of life and better management of medical outcomes (17). However, this framework considers not only how goals can lead to positive outcomes, but how goal changes can lead to conflicts and result in more negative outcomes such as lower quality of life.

In young cancer survivors, health status may affect the pursuit of personal goals and relate to young adults' subjective well-being (18). Furthermore, among adults with cancer, disrupted or blocked goals can lead to increased distress and depression, and lower quality of life (19, 20). Studies comparing young adults with a history of paediatric disease with healthy peers show that the 'course of life', such as developmental and social trajectories, is often delayed and fewer milestones are achieved $(21,22)$. To date, much of the literature on vocational and personal goal disruptions has focused on younger children, who may have more time to catch-up on education or older adults who have finished school and are experienced employees with a track record of employment $(9,21-24)$. 
Less attention has been given to educational and vocational goal disruption in AYA cancer patients $(17,25)$. Navigating goal disruption may be both more important to AYAs' sense of self and more difficult as their adult coping skills are only emerging. Therefore this study aims to explore the lived experiences (what it was like, what the challenges might have been) of AYAs as an entry point to understanding AYAs' challenges returning to school/work and their goal disruptions.

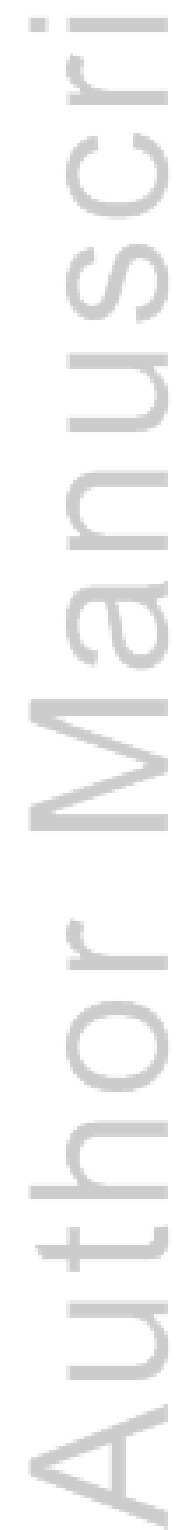

This article is protected by copyright. All rights reserved. 


\section{Methods}

\section{Participants and recruitment}

We recruited AYAs aged 15-25years who had completed cancer treatment $\leq 24$ months. The age range was based on the definition used by Cancer Australia (26). Interviews were undertaken as part of baseline data collection for a larger randomised controlled trial of a supportive intervention, Recapture Life (27). Participants were recruited from seven hospitals around Australia (via mailed invitation packages and posters/flyers in clinic waiting rooms), Facebook advertisements and through cancer-related community support groups. Invitation packages including an opt-in card were addressed from the treating medical and research professionals at each site. If we did not receive a response we contacted AYAs by telephone after 3-4 weeks. No financial compensation was offered. Ethical approval was obtained from the institutional review boards at each study site (main initial ethics: South Eastern Sydney Local Health District, HREC ref. no. 12/068), and written informed consent was obtained from all participants. Due to local ethics and privacy restrictions we were not able to obtain information about the demographic and clinical characteristics of non-respondents.

\section{Interview}

Participants answered the questions of the Psychosocial Adjustment to Illness Scale (PAIS) (28) via an audio-recorded telephone interview with a trained research officer (SE, ED or ER). The PAIS is a structured interview that explores the psychological and social adjustment of patients to their illness via 46 items across seven domains. It has previously been used and validated in adult patient populations, including cancer and other chronic diseases (29). For 
the current study, language was adapted to be age-appropriate for AYAs. The vocational environment section was the focus of the current study (Appendix 1). Participants answered questions that referred specifically to the impact of cancer on their vocational functioning in the last 30 days which refers to a snapshot of time after finishing cancer treatment. The question on performance level also took daily tasks into consideration.

Analysis

Interviews were transcribed verbatim and coded line-by-line, informed by the methodology of Miles and Huberman (30). Content was analysed, themes within each section of the vocational environment section were identified through inductive thematic analysis and illustrative quotes extracted. To increase data reliability, prominent topics were derived and reviewed by two coders (JV and BM), who met regularly to address any disagreements. After the interviews were completed and the qualitative data was analysed, one researcher then scored participants' answers to the PAIS interview questions on a four point Likert scale $(0=$ no impairment, $3=$ marked impairment; Table 2$)$, in accordance with the PAIS scoring system. Ten percent of the interviews were double coded to increase validity and reliability, any disagreements were addressed. Inter-rater reliability was $80.2 \%$. We used findings of the thematic analysis to explain quantitative findings of the PAIS scoring (31). Descriptive statistics were used to calculate proportions and describe characteristics of participants. Descriptive statistics were analysed using the statistical software package Stata 14 (StataCorp, 2015). 


\section{Results}

\section{Participants}

Forty-two AYAs (50\% female) were interviewed (Table 1). The mean age at interview was 20.5 years and mean time since treatment completion was 8.0 months. Before diagnosis, 15 AYAs were at school (Year 12/final year of High School in Australia or below, 35.7\%), 10 were at university $(23.8 \%), 16(38.1 \%)$ were engaged in full-time employment, and one (2.4\%) was between school and university studies.

We identified three main themes from the PAIS interviews: (1) barriers to school/work reintegration, (2) performance at school, and work and (3) shifts in goals in early survivorship.

\section{Barriers to school and work reintegration}

Disease-related difficulties: Physical and cognitive. Reintegration into schooling or paid employment was challenging for AYAs for different reasons. Most AYAs described experiencing cognitive and/or physical difficulties. Compared with their previous vocational functioning, the research team scored $12(28.6 \%)$ as experiencing a mild impairment, 14 $(33.3 \%)$ experiencing moderate impairment, and three $(7.1 \%)$ experiencing marked impairment (Table 2).

With regards to cognitive difficulties, some survivors reported concentration problems (“...it kind of distracts me and then I [lose] my train of thoughts like immediately...” [male, 18 years-old, 8 months post-treatment, non-Hodgkin's lymphoma]), loss of energy (“...my 
energy is...cut in half" [female, 22 years-old, 12 months post-treatment, Hodgkin's lymphoma]), tiredness or fatigue, "chemo-brain”. Others reported problems with mood and motivation. As one AYA reported, "[the cancer] impaired me in a mental sense... it's harder to keep motivated" [male, 23 years-old, 19 months post-treatment, Hodgkin's lymphoma].

In terms of physical difficulties interfering with return to school and work, AYAs reported problems with pain, sitting or standing for a long time, and heavy lifting. As one AYA remarked, "I haven't been able to go back because of that leg pain...I wouldn't be able stand up for 5 hours a day" [male, 21 years-old, 11 months post-treatment, soft tissue sarcoma].

Social factors. The majority of AYAs were scored as experiencing no interpersonal conflicts upon returning to school/work $(n=24,57.1 \%)$. A quarter $(n=12,28.6 \%)$ were scored as experiencing a slight increase, while six described a moderate to marked increase ( $\mathrm{n}=6$ (5 male), 14.4\%). Challenges included feeling left behind, disconnected ("I feel alone. Ifeel isolated, I feel like I don't connect to people that much" [female, 25 years-old, 5 months post-treatment, Hodgkin's lymphoma]; "Most I would have called friends before I would now call acquaintances" [male, 21-years old, 11 months post-treatment, soft tissue sarcoma]), and different from peers in terms of appearance ("Because I've lost my hair, a lot of people just sort of stare at me, so that is quite awkward and quite embarrassing” [female, 17 years-old, 5 months post-treatment, clear cell cervical cancer]). Some AYAs described feeling more mature than their peers in terms of placing less importance on others' perceptions ('I don't even care what people think of me" [female, 18 years-old, 9 months post-treatment, acute myeloid leukemia] and having a different outlook on life ("I would say tensions arise because my attitude towards life has changed" [male, 18-years old, 5 months, seminoma]). 


\section{Performance at school and work}

Although many AYAs reported at least some challenges returning to school or work, most were scored as perceiving that their personal performance was adequate or only slightly inadequate $(\mathrm{n}=38,90.5 \%)$. Four AYAs were scored as having moderate or markedly inadequate performance, commonly attributed to the ongoing cognitive effects of treatment: “...the illness had an effect on my ability to concentrate, remain focused for long periods of time" [male, 18 years old, 10 months post-treatment, seminoma]. Most participants reported no time lost at school or work in the last 30 days $(n=33,82.5 \%)$. Four $(10 \%)$ reported one week lost, one (2.5\%) reported two weeks lost and two (5\%) more than two weeks lost. Common reasons for time lost included sick leave and medical appointments.

3. Shifts in educational and vocational goals in early survivorship

Most AYAs were scored as perceiving that their education or vocation was equally as important $(n=16,38.1 \%)$ or of greater importance $(n=10,23.8 \%)$ to them after cancer as before their diagnosis, and 17 AYAs were scored as having goals that remained unchanged (40.5\%). "I thought I had to [change goals], but coming out of it, I can live life again and keep the same goals” [male 25 years-old, 18 months post-treatment, non-hodgkin's lymphoma]. Nevertheless, over half of the AYAs were scored as having goals that were either slightly modified $(n=15,35.7 \%)$, significantly reduced $(n=7,16.7 \%)$, or markedly different $(n=3,7.1 \%)$.

This article is protected by copyright. All rights reserved. 
Although the reasons for goal modification varied, for many participants this represented a positive shift newly informed by values such as health $(n=6)$, family $(n=1)$, enjoyment $(n=9)$, and altruism $(\mathrm{n}=6)$.

Health-informed goal modification. As one AYA described: "Before [the cancer, I planned] I would immediately start university and working straight after high school. Because of the illness I understand now that my health takes a front seat..." [male, 18 yearsold, 10 months post-treatment, seminoma]. This fits with the broader idea of a shift in perspective: "I used to worry about getting something done, but then I realised it is only a small problem compared to the big picture" [male, 16 years-old, 1 month post-treatment, sarcoma]. AYAs also indicated a desire to prioritise their self-care "The jobs I was planning to do were a lot more hard-core than what I think I will start out doing now because I want to take things gently" [female, 23 years-old, 9 months post-treatment, metastic neuroendocrine carcinoid tumour of appendix].

Enjoyment-informed goal modification. Other AYAs indicated a shift in goals related to fostering feelings of satisfaction and enjoyment- "I just want to do things that I enjoy rather than being a miserable person that hates their job" [male, 19 years-old, 12 months post-treatment, testicular cancer].

Altruism-informed goal modification. For some young people their vocation goals were directly informed by their cancer experience; for example, a desire to work in the health or charity sector: “...now I don't so much mind about my career, I want to have a purpose 
with my job and help people” [female, 23 years-old, 5 months post-treatment, Hodgkin's lymphoma].

Goal constraints. In contrast, four young people acknowledged that the uncertainty associated with their health made it harder to focus on long-term goals. For example one male survivor said: “no point making really long-term plans because anything can happen... I struggle to make long-term goals now" [male, 19 years-old, 12 months post-treatment, Hodgkin's lymphoma]. In addition, the theme of 'goal conflict' emerged, which is defined as encountering different barriers such as physical, practical or psychological barriers to the initial set goals (17). AYAs reported compromised physical or cognitive abilities to achieve their goals. "I haven't been able to take on as much study as I would like to. I'm still doing part time and I want to increase it next year if I'm feeling up to it" [female, 24 years-old, 4 months post-treatment, liver cancer] or as another said: "I'm just exhausted and mentally drained as well" [female, 24 years-old, 11 months post-treatment, Hodgkin's lymphoma]. 


\section{Discussion}

We know that goals are critical in the AYA years, yet we know little about how AYAs with cancer navigate educational/vocational goals when they are disrupted. This study is one of the first to explore how young cancer survivors navigate disruptions to vocational and educational goals during a critical developmental period. The use of the structured PAIS interview was a strength in terms of assessing this issue in a comprehensive, multi-faceted manner. Participants in this study described a variety of barriers to successful school/work reintegration, including cognitive, physical and social factors. However, most AYAs did not see their daily performance as compromised and reported placing equal importance on their educational and vocational pursuits as before their cancer diagnosis. Our results revealed that for many AYAs-early survivorship is a time of goal adjustment; but importantly, goal modifications were often positive and driven by personal values. When goals were constrained, this was influenced by a sense of uncertainty about the future or the physical/cognitive effects of treatment.

AYAs described several barriers to work/school reintegration. In line with existing research, our participants described diminished cognitive and physical capacities in the early survivorship period, namely fatigue (32), concentration problems or "chemo-brain" (33), and pain (34). Fatigue, the most common treatment-related side effect and greatest contributor to lost workplace productivity in adult cancer survivors (35), may require particular consideration and intervention in this population. Social factors also played a role in AYAs' experience of the return to work/school. The sense of being 'left behind', disconnected from peers, or insecure about physical appearance may place AYA cancer survivors at increased 
risk of low self-esteem and compromised self-identity (9). AYAs might not have developed adult coping skills and have fewer life experiences to navigate conflicts. Therefore, the role of school/work in fostering a sense of normality, forming self-identity and purpose, and quality of life (9) may be particularly crucial for AYAs.

Several results from the current study support the conceptual framework that AYA cancer survivors are a resilient group who may even experience post-traumatic growth (36), defined as a greater appreciation of life and a stronger sense of one's personal strengths and values as a result of the cancer experience (37). Despite experiencing challenges, few AYAs indicated that they perceived their performance to be inadequate and reported little time lost at work/school due to cancer-related factors in the 30 days prior to their interview. In contrast we found that many AYAs experienced a positive shift and reprioritisation of their educational/vocational goals in line with values of health, enjoyment, and altruism. Echoing previous studies in adult patients, our findings suggest that survivors may attach less importance to work (38) and take a more balanced approach to life (39) following cancer. They may also value career goals less and focus more on activities creating meaning and enjoyment of life (38). AYAs' sense of self and well-being may be enhanced by their ability to reprioritize goals $(21,22)$.

Not all AYAs reported a positive shift in goals. Some reported goal constraints resulting in goal conflicts, which were mainly related to limited physical or cognitive abilities or uncertainty about future health. Difficulty achieving personal goals is associated with elevated distress, symptoms of depression and lower quality of life $(40,41)$. Additionally, AYAs' course of life might be delayed which puts them at greater risk for poorer functioning, 
lower quality of life and distress later in life $(12,22)$. Therefore, when planning a return to school/work these goal conflicts need to be taken into account and AYAs may need additional guidance from educational and vocational advisors within school and/or from community and government organisations around meaningful goal-setting (42). AYAs experience different barriers and opportunities and therefore their needs are very subjectivesome might have acquired sufficient coping skills, while others might need additional support to develop these. Therefore interventions should be tailored to specific groups of AYAs encountering certain barriers and conflicts. A previous systematic review suggested that structured coping skills were effective in improving AYA's psychological and quality of life outcomes (43). Supporting AYAs to develop adaptive coping and problem-solving skills around challenges to their imagined future goals may form part of future educational/vocational interventions.

\section{Study limitations}

The conclusions of this study might be limited to the extent that the results are a snapshot of experiences in early survivorship, as participants' education and vocation adjustment was only assessed 'in the last 30 days' (as per the methodology of the PAIS interview) (28). Additionally, as we do not have information on non-respondents, it is possible that AYAs who self-selected to participate may differ from non-respondents in terms of their functioning. Given that this study offered a supportive intervention, it is possible that participants may either have been systematically coping better (managing a research study involving meeting other AYAs and talking about experiences) or equally may have been more distressed (needing a psychological intervention). 
Our results are based on the subjective functioning of AYAs and might also differ if assessed in an observational study. Further, results might not be generalizable, as Australian health and education system might be different to other countries. As the focus of this study was exploring the lived experiences of AYAs with cancer, we did not include AYAs without cancer as a comparison group even though they might also experience challenges in these areas due to their developmental stage. We only have limited information on positive effects, for example, on relationships at school/work. Future studies should therefore assess the positive effects of cancer on AYAs in more depth. However, further research is also warranted to explore longer term experiences of AYA cancer survivors' education and vocation pathways including assessing clinical and socio-demographic factors which influence AYAs' goal disruption and resilience during the post-treatment period.

\section{Clinical implications}

A better understanding of AYA cancer survivors' vocational adjustment has important practical and clinical implications. AYAs should be screened for educational and vocational difficulties as suggested by the psychosocial standard of care guidelines (44). Further access to interventions tailored to AYAs' needs and support systems such as engagement with educational advisors or promoting use of online forums/support groups for those with identified difficulties could be offered $(42,43,45)$. If young cancer survivors do not successfully reintegrate into the education or employment system in early survivorship they may experience long-term implications in terms of earning and career potential (7), course of life (22), mental health (46) and social well-being (5). 


\section{Conclusion}

Support services for AYA cancer survivors need to take into account the various challenges of early survivorship—cognitive, physical and social—whilst recognising that this is a resilient group who may nevertheless be profoundly affected by their experiences.

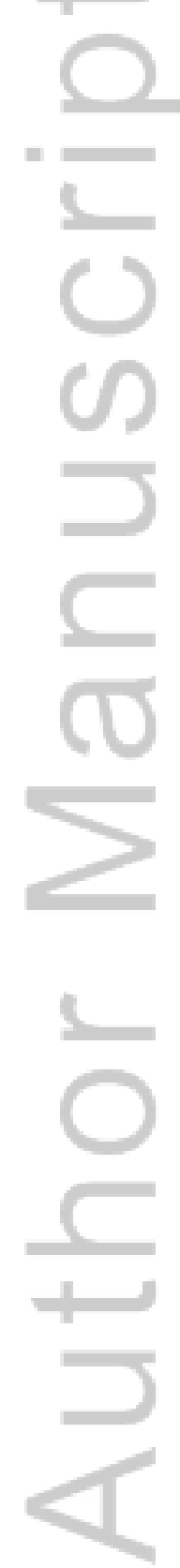

This article is protected by copyright. All rights reserved. 
Acknowledgments: The authors wish to thank all of the young people who participated in this study. We acknowledge the contribution of Eden Robertson, Emma Doolan, Kate Marshall, Sanaa Mathur, Helen Wilson, and Emily Spencer, as well as the support of the wider Recapture Life Working Party, including Richard Bryant (University of New South Wales), Phyllis Butow (University of Sydney), Pandora Patterson (CanTeen Australia), Antoinette Anazodo (Sydney Youth Cancer Service), Kate Thompson and Lucy Holland (OnTrac@ PeterMac, VIC), Michael Osborn (Youth Cancer Service SA/NT), Meg Plaster Youth Cancer Service, WA), Belinda Matigian and Ms Lyndal Gray (AYA Cancer Service, Princess Alexandra Hospital, QLD), and Belinda Barton (Children's Hospital Westmead, SW). The Recapture Life study was co-funded by a beyond blue and Cancer Australia project grant (ID: 1022868), and by a Cancer Council NSW Program Grant (PG16-02) with the support of the Estate of Late Harry McPaul. Janine Vetsch is supported by the Swiss National Science Foundation (Doc.Mobility grant P1LUP3_162120). Ursula Sansom-Daly is supported by an Early Career Fellowship from the Cancer Institute of NSW (ID: 14/ECF/111) and an Early Career Fellowship from the National Health and Medical Research Council of Australia (APP1111800). Claire Wakefield is supported by a Career Development Fellowship from the National Health and Medical Research Council of Australia (APP1067501). The Behavioural Sciences Unit is supported by the Kids with Cancer Foundation. 


\section{References}

1. Patton GC, Sawyer SM, Ross DA, Viner RM, Santelli JS. From Advocacy to Action in Global Adolescent Health. The Journal of adolescent health : official publication of the Society for Adolescent Medicine. 2016;59(4):375-7.

2. Bellizzi KM, Smith A, Schmidt S, Keegan TH, Zebrack B, Lynch CF, et al. Positive and negative psychosocial impact of being diagnosed with cancer as an adolescent or young adult. Cancer. 2012;118(20):5155-62.

3. Zebrack BJ. Psychological, social, and behavioral issues for young adults with cancer. Cancer. 2011;117(10 Suppl):2289-94.

4. Patterson P, McDonald FE, Zebrack B, Medlow S. Emerging issues among adolescent and young adult cancer survivors. Seminars in oncology nursing. 2015;31(1):53-9.

5. Warner EL, Kent EE, Trevino KM, Parsons HM, Zebrack BJ, Kirchhoff AC. Social well-being among adolescents and young adults with cancer: A systematic review. Cancer. 2016;122(7):1029-

37.

6. Parsons HM, Harlan LC, Lynch CF, Hamilton AS, Wu XC, Kato I, et al. Impact of cancer on work and education among adolescent and young adult cancer survivors. Journal of clinical oncology : official journal of the American Society of Clinical Oncology. 2012;30(19):2393-400.

7. Guy GP, Jr., Yabroff KR, Ekwueme DU, Smith AW, Dowling EC, Rechis R, et al. Estimating the health and economic burden of cancer among those diagnosed as adolescents and young adults. Health affairs (Project Hope). 2014;33(6):1024-31.

8. Begg S, Vos T, Barker B, Stevenson C, Stanley L, Lopez A. The burden of disease and injury in Australia 2003. Cat noPHE 82 Canberra: AlHW. 2007.

9. Wells M, Williams B, Firnigl D, Lang H, Coyle J, Kroll T, et al. Supporting 'work-related goals' rather than 'return to work' after cancer? A systematic review and meta-synthesis of 25 qualitative studies. Psychooncology. 2013;22(6):1208-19.

10. Miedema B, Hamilton R, Easley J. From "invincibility" to "normalcy": coping strategies of young adults during the cancer journey. Palliative \& supportive care. 2007;5(1):41-9.

11. Kwak M, Zebrack BJ, Meeske KA, Embry L, Aguilar C, Block R, et al. Prevalence and predictors of post-traumatic stress symptoms in adolescent and young adult cancer survivors: a 1-year followup study. Psychooncology. 2013;22(8):1798-806.

12. Kwak M, Zebrack BJ, Meeske KA, Embry L, Aguilar C, Block R, et al. Trajectories of psychological distress in adolescent and young adult patients with cancer: a 1-year longitudinal study. Journal of clinical oncology : official journal of the American Society of Clinical Oncology. 2013;31(17):2160-6.

13. McLoone JK, Wakefield CE, Butow P, Fleming C, Cohn RJ. Returning to School After Adolescent Cancer: A Qualitative Examination of Australian Survivors' and Their Families' Perspectives. Journal of adolescent and young adult oncology. 2011;1(2):87-94.

14. Pini S, Hugh-Jones S, Gardner PH. What effect does a cancer diagnosis have on the educational engagement and school life of teenagers? A systematic review. Psychooncology. 2012;21(7):685-94.

15. van Muijen P, Weevers NL, Snels IA, Duijts SF, Bruinvels DJ, Schellart AJ, et al. Predictors of return to work and employment in cancer survivors: a systematic review. European journal of cancer care. 2013;22(2):144-60.

16. Austin JT, Vancouver JB. Goal constructs in psychology: Structure, process, and content. Psychological Bulletin. 1996;120(3):338-75. 
17. Schwartz L, Drotar D. Defining the Nature and Impact of Goals in Children and Adolescents with a Chronic Health Condition: A Review of Research and a Theoretical Framework. Journal of Clinical Psychology in Medical Settings. 2006;13(4):390-402.

18. Schwartz LA, Drotar DCGC. Health-Related Hindrance of Personal Goal Pursuit and WellBeing of Young Adults with Cystic Fibrosis, Pediatric Cancer Survivors, and Peers without a History of Chronic Illness. J Pediatr Psychol. 2009:jsn144.

19. Offerman MP, Schroevers MJ, van der Velden LA, de Boer MF, Pruyn JF. Goal processes \& self-efficacy related to psychological distress in head \& neck cancer patients and their partners. European journal of oncology nursing : the official journal of European Oncology Nursing Society. 2010;14(3):231-7.

20. Stefanic N, Iverson DC, Caputi P, Lane L. Examining the influence of personal goal interference and attainability on psychological distress in non-metastatic breast cancer patients. European journal of cancer care. 2016:n/a-n/a.

21. Stam H, Hartman EE, Deurloo JA, Groothoff J, Grootenhuis MA. Young adult patients with a history of pediatric disease: impact on course of life and transition into adulthood. The Journal of adolescent health : official publication of the Society for Adolescent Medicine. 2006;39(1):4-13. 22. Stam H, Grootenhuis MA, Last BF. The course of life of survivors of childhood cancer. Psychooncology. 2005;14(3):227-38.

23. Stefanic N, Caputi P, Lane L, Iverson DC. Exploring the nature of situational goal-based coping in early-stage breast cancer patients: A contextual approach. European journal of oncology nursing : the official journal of European Oncology Nursing Society. 2015;19(6):604-11.

24. Stefanic N, Caputi P, Iverson DC. Investigating physical symptom burden and personal goal interference in early-stage breast cancer patients. Supportive care in cancer : official journal of the Multinational Association of Supportive Care in Cancer. 2014;22(3):713-20.

25. Schwartz LA, Brumley LD. What a Pain: The Impact of Physical Symptoms and Health Management on Pursuit of Personal Goals Among Adolescents with Cancer. J Adolesc Young Adult Oncol. 2016.

26. Australia C. National Service Delivery Framework for Adolescent and Young Adults with Cancer.

https://canceraustraliagovau/sites/default/files/publications/national service delivery framework for adolescents and young adults with cancer teen 52f301c25de9bpdf. 2008.

27. Sansom-Daly UM, Wakefield CE, Bryant RA, Butow P, Sawyer S, Patterson P, et al. Online group-based cognitive-behavioural therapy for adolescents and young adults after cancer treatment: A multicenter randomised controlled trial of Recapture Life-AYA. BMC Cancer.12:339.

28. Derogatis LR. The psychosocial adjustment to illness scale (PAIS). Journal of Psychosomatic Research. 1986;30(1):77-91.

29. Kolokotroni P, Anagnostopoulos F, Missitzis I. Psychosocial Adjustment to Illness Scale: Factor structure, reliability, and validity assessment in a sample of Greek breast cancer patients. Women \& health. 2016:1-18.

30. Miles B, Huberman A. Qualitative data analysis: An expended sourcebook. London, UK, Sage Publications 1994.

31. Pluye $\mathrm{P}$, Hong QN. Combining the power of stories and the power of numbers: mixed methods research and mixed studies reviews. Annual review of public health. 2014;35:29-45. 
32. Yi J, Kim MA, Tian T. Perceived long-term and physical health problems after cancer: adolescent and young adult survivors of childhood cancer in Korea. European journal of oncology nursing : the official journal of European Oncology Nursing Society. 2014;18(2):145-50.

33. Nelson CJ, Nandy N, Roth AJ. Chemotherapy and cognitive deficits: mechanisms, findings, and potential interventions. Palliative \& supportive care. 2007;5(3):273-80.

34. Glare PA, Davies PS, Finlay E, Gulati A, Lemanne D, Moryl N, et al. Pain in cancer survivors. Journal of clinical oncology : official journal of the American Society of Clinical Oncology. 2014;32(16):1739-47.

35. Curt GA, Breitbart W, Cella D, Groopman JE, Horning SJ, Itri LM, et al. Impact of cancerrelated fatigue on the lives of patients: new findings from the Fatigue Coalition. The oncologist. 2000;5(5):353-60.

36. Arpawong TE, Oland A, Milam JE, Ruccione K, Meeske KA. Post-traumatic growth among an ethnically diverse sample of adolescent and young adult cancer survivors. Psychooncology. 2013;22(10):2235-44.

37. Tedeschi RG, Calhoun LGCGC. The Posttraumatic Growth Inventory: measuring the positive legacy of trauma. J Trauma Stress. 1996;9:455-71.

38. Maunsell E, Brisson C, Dubois L, Lauzier S, Fraser A. Work problems after breast cancer: an exploratory qualitative study. Psychooncology. 1999;8(6):467-73.

39. Main DS, Nowels CT, Cavender TA, Etschmaier M, Steiner JF. A qualitative study of work and work return in cancer survivors. Psychooncology. 2005;14(11):992-1004.

40. Dunne E, Wrosch C, Miller GE. Goal disengagement, functional disability, and depressive symptoms in old age. Health psychology : official journal of the Division of Health Psychology, American Psychological Association. 2011;30(6):763-70.

41. Brandtstädter J, Rothermund K. The Life-Course Dynamics of Goal Pursuit and Goal Adjustment: A Two-Process Framework. Developmental Review. 2002;22(1):117-50.

42. Sawyer SM, McNeil R, McCarthy M, Orme L, Thompson K, Drew S, et al. Unmet need for healthcare services in adolescents and young adults with cancer and their parent carers. Supportive care in cancer : official journal of the Multinational Association of Supportive Care in Cancer. 2017;25(7):2229-39.

43. Sansom-Daly UM, Peate M, Wakefield CE, Bryant RA, Cohn RJ. A systematic review of psychological interventions for adolescents and young adults living with chronic illness. Health psychology : official journal of the Division of Health Psychology, American Psychological Association. 2012;31(3):380-93.

44. Wiener L, Kazak AE, Noll RB, Patenaude AF, Kupst MJ. Standards for the Psychosocial Care of Children With Cancer and Their Families: An Introduction to the Special Issue. Pediatric blood \& cancer. 2015;62 Suppl 5:S419-24.

45. Stone DS, Ganz PA, Pavlish C, Robbins WA. Young adult cancer survivors and work: a systematic review. Journal of cancer survivorship : research and practice. 2017.

46. Sawyer SM, Afifi RA, Bearinger LH, Blakemore S-J, Dick B, Ezeh AC, et al. Adolescence: a foundation for future health. The Lancet.379(9826):1630-40. 
Table 1. Participant characteristics $(\mathrm{N}=42)$

Survivors

Socio-demographic characteristics

Sex: N (\%)

$\begin{array}{ll}\text { Male } 21(50.0 \%) & \end{array}$

Female

$21(50.0 \%)$

\begin{tabular}{lc}
\hline Mean age at interview in years (SD), range & $20.5(3.0), 15-26$ \\
\hline Mean age at diagnosis in years (SD), range & $19.0(3.3), 11-25$ \\
\hline
\end{tabular}

Mean time since treatment completion (in months;

SD), range

$8.3(4.6), 1-19$

Cancer diagnosis

Solid cancer

$17(39.5 \%)$

Lymphoma/Leukaemia

$18(41.9 \%)$

Brain tumour

$3(7.0 \%)$

Education

End of secondary education or below

$24(55.8 \%)$

University or post-graduate

$7(16.3 \%)$

Other $^{\mathrm{b}}$

$7(16.3 \%)$

Country of birth

Australia

$36(92 \%)$

Other

$3(7.7 \%)$

Remoteness Index of Australia

Inner region

$26(68.4 \%)$

Outer region

$9(23.7 \%)$

Rural

$3(7.9 \%)$

Numbers do not always add up due to missing values 
${ }^{a}$ Participants only provided approximate ages (age in years, not in months), ${ }^{b}$ Other: Technical college, diploma, apprenticeship

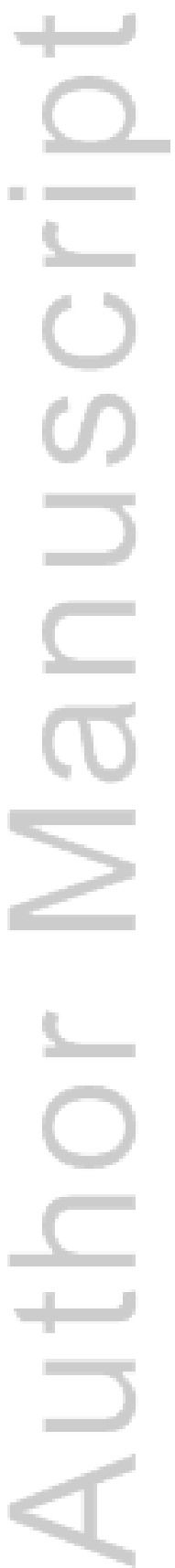

This article is protected by copyright. All rights reserved. 
Table 2. AYAs' level of functioning across the PAIS Vocational Environment section, scored by the researcher

\begin{tabular}{llr}
\hline $\begin{array}{l}\text { How adequately are you able to do your } \\
\text { job/study/school work now? }\end{array}$ & $\begin{array}{l}\text { Personal performance } \\
\text { evaluation }\end{array}$ & N (\%) \\
& $\begin{array}{l}\text { Complete adequacy } \\
\text { Slight inadequacy }\end{array}$ & $15(35.8)$ \\
& Moderate inadequacy & $3(7.1)$ \\
& Marked inadequacy & $1(2.4)$
\end{tabular}

Thinking about the last 30 days has your diagnosis Vocational impairment in any way impaired your ability to do your ..... and if so how much?

No impairment

Mild impairment

Moderate impairment

Marked impairment

During the past 30 days, have you lost any time at work/uni/school due to your diagnosis?
Self-reported time lost on the job in the last 30 days

3 days or less

1 week

2 weeks

Greater than 2 weeks

$2(4.8)$
Is your job/school as important to you now as it was before your illness?

\author{
Vocational investment \\ Equal or greater importance \\ $26(61.9)$ \\ Only slightly less important \\ $11(26.2)$ \\ than before \\ Clear loss of investment in \\ $5(11.9)$
}


vocational situation

Minimal investment in

remaining in vocation

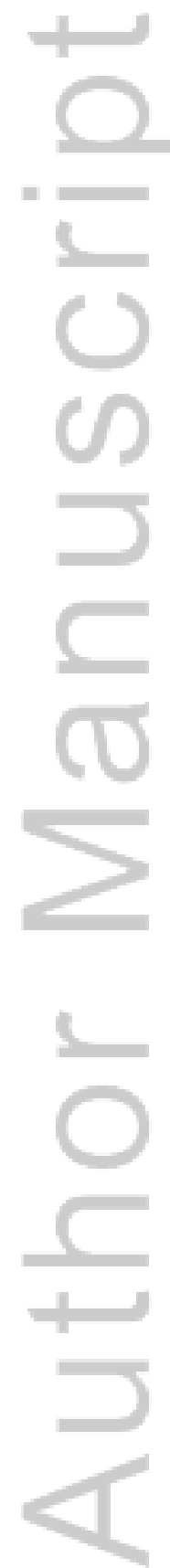

This article is protected by copyright. All rights reserved. 


\section{Table 2 contd.}

Have you had to change your basic goals regarding Vocational goals your job/study as a result of your diagnosis?

Goals unchanged

$17(40.5)$

Slight modification

$15(35.7)$

Significant reduction

$7(16.7)$

Marked modification

$3(7.1)$

Again in the past 30 days have you noticed an

Interpersonal conflict increase in arguments, tension or difficulty getting along with your co-workers/peers/class mates since your diagnosis?

None

Slight increase

Moderate increase

Marked increase

$1(2.4)$

NB: Participants' qualitative responses were scored by the researcher in accordance with the PAIS scoring system.

This article is protected by copyright. All rights reserved. 